\author{
İbrahim Özkan Akıncı \\ Ahmet Başel \\ Altay Sencer \\ Yavuz Aras \\ Aydın Aydöseli \\ Serra Sencer \\ Candan Gürses \\ Günseli Orhun \\ Perihan Ergin Özcan \\ Lütfi Telci
}

\section{Anevrizmal Subaraknoid Kanama Hastalarında Beyin Ölümü Kararının Verilmesinde Elektroensefalografinin Önemi}

\author{
Importance of EEG as a Confirmatory Test For Brain \\ Death Decision in Aneurysmal SAH Patients
}

Geliş Tarihi/Received: 13.112012

Kabul Tarihi/Accepted: 04.12.2012

Türk Yoğun Bakım Derneği Dergisi, Galenos Yayınevi tarafından basılmıștır.

Journal of the Turkish Society of Intensive Care, published by Galenos Publishing. ISNN: 1300-5804

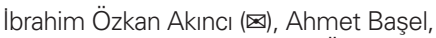
Günseli Orhun, Perihan Ergin Özcan, Lütfi Telci Istanbul Üniversitesi Istanbul Tıp Fakültesi, Anesteziyoloji ve Reanimasyon Anabilim Dalı, Istanbul, Türkiye

Altay Sencer, Yavuz Aras, Aydın Aydöseli Istanbul Üniversitesi Istanbul Tıp Fakültesi, Nöroşirürji Anabilim Dalı, Istanbul, Türkiye

Serra Sencer

Istanbul Üniversitesi Istanbul Tıp Fakültesi, Radyoloji Anabilim Dalı, Istanbul, Türkiye

Candan Gürses

Istanbul Üniversitesi Istanbul Tıp Fakültesi, Nöroloji Anabilim Dalı, Istanbul, Türkiye

E-posta: iozkana@yahoo.com

Tel.: +90 2124142000 / 32554
ÖZET Amaç: Klinik muayene ile beyin ölümü geliştiği tespit edilen anevrizmal subaraknoid kanama (aSAK) hastalarında destekleyici test olarak serebral dolaşımın gösterildiği testlerin yerine, kortikal aktiviteyi gösteren elektro ensefalografinin (EEG) kullanımını değerlendirmek.

Gereç ve Yöntem: Haziran 2010 ve 2011 döneminde aSAK tanısıyla Nöroşirürji Yoğun Bakım ünitesine yatan tüm hastalar takibe alındı. Bu hastalardan klinik muayenede beyin ölümü saptananlara, destekleyici test olarak serebral dolaşımı gösteren serebral anjiografi (DSA) uygulandiktan sonra beynin kortikal aktivitesini gösteren EEG yapıldı ve sonuçlar değerlendirildi.

Bulgular: Bir yıllık takip döneminde aSAK tanısı ile 37 hasta servisimize alındı. Bu hastalardan 4'ünde klinik beyin ölümü tespit edildi. DSA değerlendirmesinde tüm hastalarda ileri derecede azalmış serebral kan akımı izlendi. Bu hastaların EEG değerlendirmesinde ise 3 'ünde EEG bulguları beyin ölümü lehine çıkarken sadece bir hastada baskılanmış elektriksel aktivite ve yaygın organizasyon bozukluğu tespit edildi. Beyin ölümü tespit edilen hastalar takip eden günlerde kaybedilirken son hasta arefleksi tablosunda ev tipi ventilatörle bakım hastası olarak bașka bir sağlık kuruluşuna uzun süreli bakım için gönderildi.

Sonuç: Destekleyici testlerin beyin ölümü tanısında uygun olmadığını söyleyen yayınlara rağmen, çalışmamız beyin ölümü tanısında destekleyici testlerin zorunlu olduğu ülkelerde EEG'nin DSA'ya göre hızlı ve daha doğru tanı konmasında yararlı olabileceği göstermektedir.

Anahtar Kelimeler: Beyin ölümü, destekleyici test, elektroensefalografi, subaraknoid kanama
SUMMARY Objective: To evaluate the efficacy of electroencephalography (EEG) and cerebral angiography (DSA) as confirmatory tests to diagnose brain death on aneurysmal subarachnoid hemorrhage (aSAH) patients. Material and Method: We prospectively evaluated all aSAH patients who were admitted to Istanbul Medical Faculty NeuroIntensive Care Unit between June 2010 and June 2011. All patients, who developed brain death according to neurologic evaluation, were evaluated again first with DSA and then EEG as confirmatory tests.

Results: Of thirty seven aSAH patients admitted to our ICU during one year period, only 4 were diagnosed with clinical brain death after neurologic evaluation. First, we performed DSA which showed all had minimal cerebral blood flow. Then EEG was performed and only one of them still showed slow wave activity which contradicted brain death but other 3 had isoelectric cerebral silence which supported brain death. These 3 patients died within two days after brain death diagnosis. However, the first patient survived but Glasgow coma score was 3 and transferred to an intermediate care unit for long term care with home type ventilator.

Conclusion: Unlike the common argument against confirmatory tests for brain death diagnosis, our study indicated EEG to be more reliable than DSA to confirm brain death in aSAH patients, considering that confirmatory test obligatory for brain death decisions.

Key Words: Brain death, confirmatory test, electroencephalography, subarachnoid hemorrhage 


\section{Giriş}

YBeyin ölümü kararının verilmesinde, hastanın tamamen ve geri dönüşümsüz olarak beyin fonksiyonlarının ortadan kalktığının gösterilmesi gereklidir. Ülkemizde bir hastaya beyin ölümü kararı verebilmek için, anestezist, nöroşirürjiyen, nörolog ve kardiyologdan oluşan dört farklı uzmanlık dalındaki hekimin yaptığı klinik testlerde negatif sonuç alınması ve bu hekim grubunun belirleyeceği destekleyici testlerden, serebral anjiografi (DSA), bilgisayarlı anjiyografi, beyin sintigrafisi, single pozitron emisyon bilgisayarlı tomografi (SPECT), pozitron emisyon tomografi (PET), transkraniyal Doppler ultrasonografi veya elektroensefalografiden (EEG) biri ile tanının doğrulanması gereklidir $(1,2)$. Ülkemiz gibi, beyin ölümü tanısında destekleyici testlerin zorunlu olduğu ülkelerde, bu testlerden hangisinin tercih edileceği konusunda belirli kurallar yoktur. Doğru tanıya en kısa sürede ulaşacak testin belirlenmesi hastanın bu tabloya sebep olan klinik durum ve beklenen seyrinin iyi değerlendirilmesi ile olabilir. Serebral anjiyografi beyin ölümü tanısı için altın standart gibi görülse de serebral dolaşımın değerlendirildiği transkraniyal Doppler ultrasonografi, bilateral karotis ve vertebral arter Doppler ultrasonıgrafisi aSAK sonucu beyin ölümü gerçekleştiği düşünülen hastalarda kesin tanı konulmasında gecikmelere sebep olabilmektedir. Bu da nakil bekleyen çok sayıda hastanın bulunduğu fakat yeterli donör bulmanın zor olduğu bizim gibi ülkelerde donör adaylarının kaybedilmesi sonucunu getirmektedir.

Anevrizmal subaraknoid kanama (aSAK) toplumda yıllık 100,000 'de 10,5 (3) oranında görülürken bu hasta grubunda genel mortalite de \%50 oranındadır (4). Hastaların \%10-15 kadarı hastaneye dahi gelemeden kaybedilirken, \%25 kadarı da kanamdan sonraki ilk 24 saat içerisinde olur ve geri kalan ölümlerin de büyük çoğunluğu ilk iki hafta içerisinde gelişir (5). aSAK hastalarının hastaneye gelişlerindeki şuur durumları, kanamanın büyüklüğü ve yaş hastanın sağkalımı ve sekel gelişimi ile direkt ilişkilidir (6). Klinik tablonun bu kadar kısa sürede gelişmesi bu hasta grubunun önemli bir sayıda donör adayı oluşturmasına rağmen, subaraknoid kanama sonucunda gelişen intrakraniyal basınç artışı ve vazospazm ile hasarın geliştiği bu tabloda serebral kan akımının az da olsa devam etmesi beyin ölümü kararı verilmesinde gecikmelere neden olabilmektedir. Biz bu çalışmamızda klinik beyin ölümü gelişen aSAK hastalarında destekleyici test olarak serebral dolaşımın gösterildiği testlerin yerine, kortikal aktiviteyi gösteren EEG'nin kullanımının değerini araştırmayı amaçladık.

\section{Gereç ve Yöntem}

Vakalar:

Çalışmamızda, Haziran 2010- Haziran 2011 tarihleri arasında Istanbul Üniversitesi, İstanbul Tıp Fakültesi, Nöroşirürji Yoğun
Bakım Ünitesi'nde aSAK tanısı ile yatırılıp takibe alınan, aSAK veri tabanındaki hastalardan, WFNS Evre 5 olan kötü nörolojik tablolu hastalar değerlendirmeye alındı. Hastane etik kurulunun izni alınarak başlanan bu gözlemsel çalışmada hastaların birinci derece yakınlarının onamı da alınarak klinik bilgileri kullanıldı. aSAK tanısı bilgisayarlı tomografi (BT) ve BT anjiyografi veya serebral anjiyografi (DSA) ile konuldu. Travmaya, arteriyovenöz malformasyona, vaskülite bağlı ve anevrizma dışı tüm SAK'lar değerlendirme dışı bırakıldı.

\section{Klinik Tedavi:}

SAK tanısıyla gelen tüm hastalara yoğun bakıma girişleri ile birlikte izovolemiyi sağlayacak düzeyde (kalp tepe atımını 120/dk altına indirecek veya kateter takılmışsa santral venöz basıncı 8$12 \mathrm{mmHg}$ olacak şekilde) \%0,09 $\mathrm{NaCl}$ solüsyonu ile sıvı resüsitasyonu ve ardından idame tedavisi başlandı. Tüm hastalara nimodipin $6 \times 2$ mg, analjezi için parasetamol, kafein, kodein içeren preparat, mide ülser profilaksisi, laktüloz ve metoklopramid başlandı. Hastaların sistolik tansiyonları 120-140 $\mathrm{mmHg}$ aralığında tutulacak düzeyde antihipertansif tedaviye başlandı. Glasgow koma skoru (GKS) <8 olan tüm hastalar entübe edilip midazolam ve remifentanil infüzyonu ile sedatize edilip BT anjiyografi veya DSA ile anevrizma tespit edilip varsa hidrosefali düzeltildikten sonra tansiyon kontrolü ile sedasyon kaldırılıp saatlik şuur muayenesi ile izlendiler.

\section{Beyin ölümü tanısı:}

Kötü dereceli olarak sınıflanan aSAK tanısı konmuş hastaların tüm sedasyonu kesildikten 48 saat sonra hala GKS 3 ise, bu hastalar beyin ölümü değerlendirmesine alındılar. Tüm hastalarda muayene edilmeden; normotermi $\left(35,5-37,0^{\circ} \mathrm{C}\right)$ ve normotansiyon sağlandı, elektrolit ve asit baz dengesizlikleri düzeltilerek stabil duruma getirildi.

Beyin ölümü tanısı için ağrılı uyarana yanıtsızlık, yutkunma refleksi, ışık, kornea refleksleri, okülosefalik ve okülovestibüler refleksler değerlendirildi, atropin ve apne testleri yapılıp hepsinden negatif sonuç alındıktan sonra tüm testler 24 saat sonra tekrarlandı. Iki kez negatif muayene bulgusu olan hastalara beyin ölümü tanısını kesinleștirmek için DSA ile değerlendirilmesi yapılıp, serebral ileri akım olup olmadığı değerlendirildi. Daha sonra da kortikal elektriksel aktiviteyi değerlendirmek için 12 kanal EEG yapıldı. EEG çekimi Amerikan Nöroloji Akademisi'nin Kalite Standartları Alt Komitesi'nin kanıta dayalı önerileri doğrultusunda (7), deneyimli EEG teknisyeni tarafından yapıldı. Çekim, elektrotlar 10-20 elektrot yerleştirme sistemine göre uygulanarak gerçekleştirildi. Elektrotlar, aralarındaki mesafe en az $10 \mathrm{~cm}$ ve impedans 100-10.000 $\Omega$ olacak şekilde yerleștirildi. Yüksek frekans filtresi $30 \mathrm{~Hz}$ ve düșük frekans filtresi ise $1 \mathrm{~Hz}$ altında olacak şekilde ayarlandı. Bir kanal tüm hastalarda kardiyak aktiviteyi ayırt edebilmek için EKG monitörizasyonu için kullanıldı. Kayıtlar standart $30 \mu \mathrm{v} / \mathrm{cm}$ ve $70 \mu \mathrm{v} / \mathrm{cm}$ kazançla yapıldı. En az 30 dakikalık kayıt yapıldı ve bu sırada vibrasyon oluşturmamak için hasta yatağına hiçbir şekilde müdahale yapılmadı. 


\section{Bulgular}

Bu gözlemsel çalışmamız süresince 99 hasta kliniğimize intraserebral anevrizma ön tanısı ile yatırılırken bu hastaların 53'ünde subaraknoid kanama mevcuttu. SAK tespit edilen bu hastaların 37'sinde anevrizma tespit edilerek aSAK tanısı konmuş ve cerrahi klipleme ya da endovasküler koilleme ile anevrizmalar kapatıldı. SAK tespit edilen hastalardan 6 tanesinde nörolojik tabloları çok kötü (GKS $<5$ ) olduğundan anevrizmanın kontrolü için girişim düşünülmedi; bu hastaların 4'ünde (\%10.8) klinik testlerde beyin ölümü tespit edilirken kalan ikisinde beyin ölümü tespit edilmedi. Kliniğimize başvurmuş 99 hastanın kalan 46 'sında ise SAK yoktu. Bunlardan 28'i rastlantısal olarak anevrizması tespit edilmişken, 11'i eski SAK, 7'si ise anevrizma rüptürü ile uyumlu başağrısı sonrası BT'de SAK görülmeyip, BT anjiyografide anevrizma tespit edilmiş ve cerrahi klipleme ya da endovasküler koilleme ile anevrizmaları kapatılış hastalardır.

aSAK ve kötü nörolojik tabloyla başvurup klinik testlerde beyin ölümü tespit edilen hastalarımızın hepsinde DSA ile serebral dolaşım değerlendirildi ve hepsinde serebral dolaşımın az da olsa devam ettiğini görüldü (Resim 1). Ardından bu hastalarda ikinci destekleyici tetkik olarak EEG yapıldı ve üç hastada kortikal aktivitenin tamamen ortadan kalktığı ve izoelektrik serebral aktivite gözlenirken (Resim 2) bir hastada düşük amplitüdlü yavaş dalgalar gözlendi (Resim 3). Ilk 3 hastada anestezi ve beyin cerrahi uzmanları bulguları beyin ölümü lehine yorumlayıp tabloyu onaylarken nöroloji ve kardiyoloji uzmanları beyin ölümü konusunda onay vermediler ve bu hastalar takip eden 72-96 saat içerisinde kardiyak arrest gelişerek kaybedildiler. EEG'de beyin ölümü gözlenmeyen hastada ise takip eden günlerde taktil uyarana sıçrama tarzında bir cevap ortaya çıktı fakat spontan

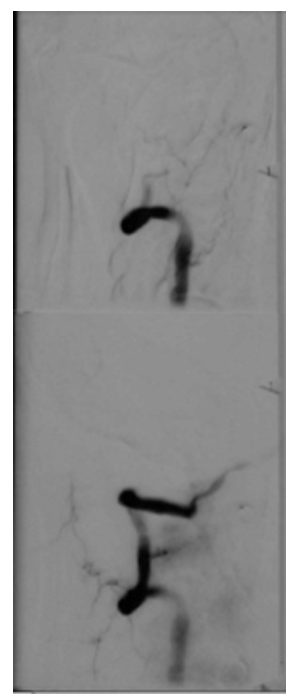

Resim 1. Serebral anjiyografi görüntüsü: Bilateral ICA antegrad akımı yavaştır. Akım dominant olarak oftalmik artere kadar devam etmekte olup, geç fazda karotis bifurkasyonu $\mathrm{A} 1$ ve $\mathrm{M1}^{\prime}$ 'e her iki tarafta minimal kontrast madde geçişi izlendiği raporu görülüp beyin ölümü lehine değerlendirilmeyen vaka solunum, yutkunma refleksi geri dönmedi. Bu hasta SAK'yı takip eden 30. gününde taktil uyarana sıçrama şeklindeki cevabı hariç hiçbir refleksinin olmaması, klinik beyin ölümü muayene bulgularının devam etmesi ve spontan solunumunun da olmamasından dolayı trakeostomisi açılıp, perkutan endoskopik gastrostomisi yapılarak, bakım hastası haline getirip ev tipi ventilatör aracılığı ile uzun dönem bakım için bir dış kliniğe gönderildi. Gittiği klinikte 45 gün daha takip ve tedavisi sürdürülen hastanın bu süre içerisinde klinik beyin ölümü tablosunun devam ettiği ve takibinin 45. gününde hipotansiyon ve kardiyak arrest gelişimi ile vefat ettiği öğrenilmiştir.

\section{Tartışma}

Çalışmamız süresince muayene bulgularına göre beyin ölümü tanısı koyduğumuz hastalarımıza yapılan destekleyici testlerin sonucunda serebral dolaşımın tüm hastalarda minimal

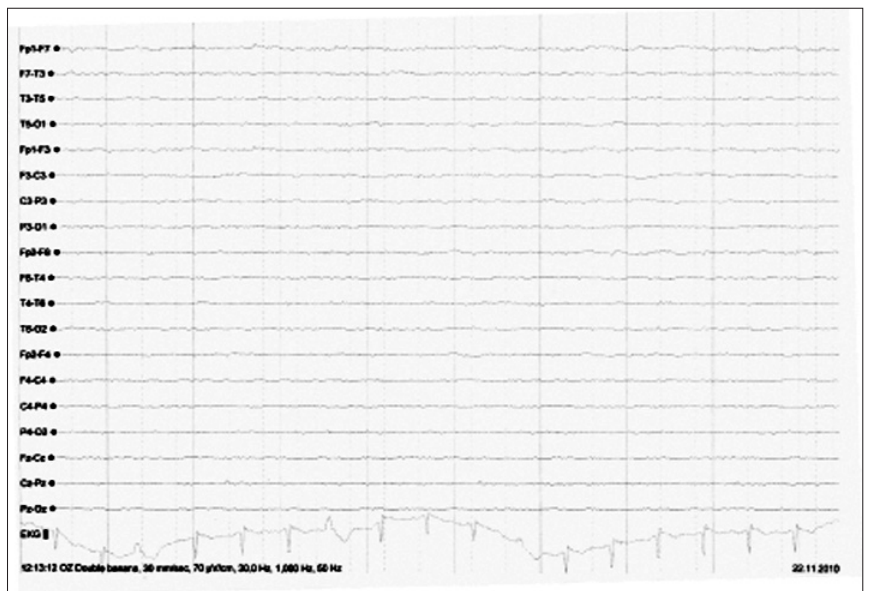

Resim 2. EEG'de beyin ölümü ile uyumlu her iki hemisferde de izoelektrik serebral aktivitenin gözlendiği vaka

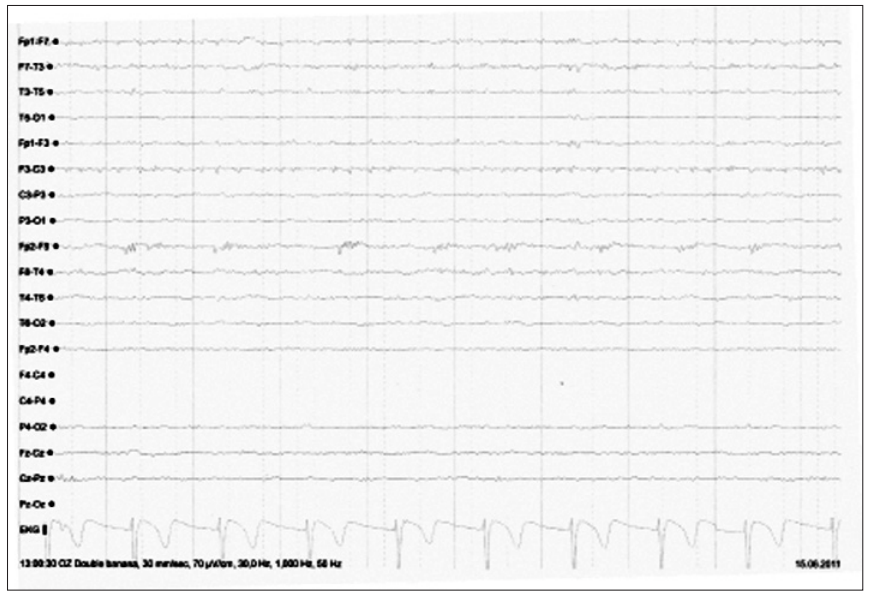

Resim 3. $E E G^{\prime}$ de beyin ölümü ile örtüşmeyen düşük amplitüdlü hızlı ritimlerden oluşan yaygın organizasyon bozukluğu tespit edilen vaka 
de olsa sürdüğü, yapılan EEG değerlendirmesinde ise sadece bir hastada zayıf EEG aktivitesi tespit edilirken kalan 3 EEG'de hiçbir kortikal aktivite gözlenmedi.

Beyin ölümünün klinik olarak tanısı koyulduktan sonra destekleyici test yapılma zorunluluğu pek çok ülkede yoktur. Bunda en önemli neden destekleyici testlerin yeterince güvenli olmamasıdır (8). Destekleyici testlerden DSA'nın klinik olarak beyin ölümü tanısı konmuş hastalarda \%5-40 oranında çeşitli düzeylerde serebral akımı gösterdiği bilinmektedir bu oran EEG içinde \%20 olarak verilmektedir $(9,10)$. Bizim sonuçlarımızda da beyin ölümü tanısı konan tüm hastalarda kısmi de olsa serebral dolaşımın görülmesi EEG değerlendirmesinde ise sadece bir hastada elektriksel aktivite görülmesi ve bu hastanın da 75 gün gibi bir sürede aynı klinik tabloda kaybedilmesi bu sonuçlarla örtüşmektedir.

Dünyada beyin ölümü tanısında kullanılan nörolojik muayene yöntemlerinden hangilerinin kullanılacağı yönünde apne testi hariç ortak bir yaklaşım yoktur. Bunun yanında ülkeden ülkeye nörolojik muayene yöntemleri, destekleyici testlerin istenmesinde büyük farklılıklar görülmektedir $(11,12)$. Gelișmiş ülkelerde kılavuzlar oluşturulmuş olsa dahi, örneğin ABD olduğu gibi eyaletler ve bölgeler arasında bile ülkeler arasında olduğu gibi beyin ölümü tespiti yapacak doktorların uzmanlık alanları, sayıları, mesleki tecrübe düzeyi konusunda dahi ciddi farklılıklar görülebilmektedir (11). Bunda karşılaşılan beyin ölümü nedenlerinin farklılıkları ve geri dönüşümsüz bir durum olduğunu ortaya koyabilmekteki zorluklar da sebep gösterilebilir. Bundan dolayı destekleyici testler kimi ülkelerde beyin ölümü tanısında zorunlu klınmıșken, kimi durumlarda da geri dönüșümsüz beyin fonksiyonları kaybı diyebilmek için biz hekimlerin elindeki önemli bir destek olarak görülmekte ve şüpheli durumlarda bir seçenek olarak ortaya konmaktadır. Yine bazı ülkelerde bulunan (kılavuzlarda farkllıklar göstermektedir), beyin ölümünün hasta yakınlarına tebliğ edilmesinden önceki bekleme süresi de bu konudaki kararı pekiștirmek adınadır. Bu çalıșmada değerlendirdiğimiz kötü nörolojik tablo ile karşılaşılan aSAK hastalarında da benzer endișeler söz konusudur. Hastalarda yaygın SAK ve artan kafa içi basıncı nedeniyle geri dönüşümsüz korteks ve beyin sapı hasarı gelișmiș olsa bile, minimal bir serebral ileri kan akımı gözlenebilmektedir. Bunda vücudun hastalığın seyrinde oluşan yaygın serebral vazospazma karșı olușturduğu sempatik cevap ve hipertansiyon neden olarak gösterilebilir. Ayrıca, beyin ölümü tanısı için serebral dolaşımın değerlendirildiği DSA uygulamasında da gerek uygulama ve gerekse değerlendirmede belirlenmiş bir kılavuzunun bulunmaması da bunda etkili olabilmektedir.

aSAK hasta grubunda sağ kalım, morbidite ve mortalitenin belirlenmesi konusunda birçok çalıșma yapılmıș ve halen yapılmaktadır. Bu bağlamda EEG'nin de aSAK hastalarının takibinde kullanımı giderek yaygınlaşmaktadır. Kötü dereceli SAK hastalarında prognozun belirlenmesinde yapılan sürekli EEG takibinin SAK'ın derecesi, hidrosefali gelişimi ve erken diffüz serebral ödem gelişimi gibi nedenlerden bağımsız olarak erken dönem prognoz konusunda anlamlı derecede yardımcı olduğu gösterilmiştir (13). Biz çalışmamızda sürekli monitörizasyon yapmamış olsak da bu çalışma ile bizim çalışmamızın sonuçlarını birleştirdiğimizde özellikle kötü dereceli aSAK hastalarında erken dönem sürekli EEG monitörizasyonu ile beyin ölümü tanısının daha erkene çekebileceği düşünülebilir fakat bu konuda yeni daha fazla sayıda hastanın değerlendirildiği çalışmalara intiyaç vardır.

aSAK hastalarının tedavisinden sorumlu olan hekimler bu hastaların tedavi süreçlerinde gelişen serebral vazospazm nedeniyle transkraniyal Doppler ultrasonu sıklıkla kullanmakta ve bu hastalarla ilgili beyin ölümü kararı verirken de destekleyici test olarak serebral dolaşımın değerlendirildiği DSA ve karotis Doppler'ini ön plana çıkarmaktadırlar. Daha önce belirttiğimiz muhtemel sebepten dolayı minimal de olsa serebral akımın görülmesi beyin ölümü kararının verilip organ bağışı için hasta yakınları ile görüşülmesi gereken süreyi geciktirmek, bu da bizim serimizde de olduğu gibi hastaların kaybedilmesine sebep olabilmektedir. Bu hastalarda serebral dolaşımın değerlendirildiği yardımcı testlerin yerine kortikal elektriksel aktivitenin değerlendirilmesinin beyin ölümü tanısı için daha erken ve daha az yanlış pozitif karar verilmesinde yardımcı olabileceği görüşündeyiz.

Organ nakli ihtiyacının giderek arttığı günümüzde, bu ihtiyacın karşılanmasında, toplumun bu konuda bilinçlendirilmesinin yanında, potansiyel donör olabilecek beyin ölümü vakalarının da hekimler tarafından hızlı tespit edilip en doğru muayene ve destekleyici testlerle doğru tanının en kısa süre içerisinde koyulmasıyla sağlanabileceği düşüncesindeyiz. Farklı sebepler ve farklı klinik seyirler neticesinde gelişebilecek beyin ölümünün tanısında muayene bulgularının yanında hukuki sorumluluğumuzu oluşturan destekleyici testin seçimi biz hekimlere iki yönlü bir vicdani sorumluluk da yüklemektedir. Nasıl intoksikasyon sonucu gelișen bir beyin ölümü tablosunda karar verirken destekleyici test olarak EEG değerlendirmesi yerine, serebral dolaşımın olmadığının gösterilmesi doğru ve hızlı kararda en etkili yöntemse, aSAK vakalarında da beyin sapı refleksleri olmayan beyin ölümü muayene bulgularını veren hastalarda beynin kortikal elektriksel aktivitenin olmadığının gösterildiği EEG'nin kullanımının hızlı ve doğru tanı konmasında yararlı olabileceği inancındayız. Ancak hala beyin ölümü konusunda dünyada kabul edilmiş tanıyı kesinleştirecek bir inceleme yöntemi olmadığı kabul edilmektedir (14).

Yalnız unutulmaması gereken beyin ölümü kararında destekleyici test olarak EEG'nin kullanılmasında dikkat edilmesi gereken pek çok ayrıntı olduğudur. Bunların başında çok hassas bir test olan EEG'nin çevresel etkilere çok açık olması nedeniyle yanlış kararlar verilmesine de sebep olabilmesidir. Bu etkileri ortadan kaldırabilmek ve doğru değerlendirmeyi yapabilmek için mutlaka dünyada kabul gören standartların sağlanması gereklidir. 


\section{Kaynaklar}

1. Organ ve doku nakli hizmetleri yönetmeliği. Resmi gazete tarih: 01-06-2000, Sayı:24066.

2. Organ ve doku nakli hizmetleri yönetmeliğinde değişiklik yapılmasına dair yönetmelik. Resmi gazete tarih: 07-032005, Sayı:25748.

3. Linn FH, Rinkel GJ, Algra A, van Gijn J. Incidence of subarachnoid hemorrhage: role of region, year, and rate of computed tomography: a meta-analysis. Stroke 1996;27:625-9.

4. Van Gijn J, Kerr RS, Rinkel GJ . "Subarachnoid haemorrhage". Lancet 2007;369:306-18.

5. Suarez JI, Tarr RW, Selman WR. Aneurysmal Subarachnoid Hemorrhage. N Engl J Med 2006;354:387-96.
6. Hijdra A, van Gijn J, Nagelkerke NJ, Vermeulen M, van Crevel H. Prediction of delayed cerebral ischemia, rebleeding, and outcome after aneurysmal subarachnoid hemorrhage. Stroke 1988;19:1250-6.

7. Eelco FM, Wijdicks EFM, Varelas PN, Gronseth GS, Greer DM. Evidence-based guideline update: Determining brain death in adults. Neurology 2010;74:1911-8.

8. Wijdicks EF. The case against confirmatory tests for determining brain death in adults. Neurology 2011;76:489-90.

9. Wijdicks EF. The case against confirmatory tests for determining brain death in adults. Neurology 2010;75:77-83.

10. Wijdicks EF, Pfeifer EA. Neuropathology of brain death in the modern transplant era. Neurology 2008;70:1234-7.
11. Wijdicks EF. Brain death worldwide: Accepted fact but no global consensus in diagnostic criteria. Neurology 2002;58:20-5.

12. Sabancı AP, Karasu A, Karadereler S, Barlas O. Beyin ölümü tanısı. Sinir Sistemi Cerrahisi Derg 2008;1:81-5.

13. Claassen J, Hirsch LJ, Frontera JA, Fernandez A, Schmidt M, Kapinos G, et al. Prognostic significance of continuous EEG monitoring in patients with poor-grade subarachnoid hemorrhage. Neurocritical Care 2006;4:103-12.

14. Joffe AR, Anton NR, Duff JP, Decaen A. A survey of american neurologists about brain death: understanding the conseptual basis and diagnotic tests for brain death. Ann Intensive Care 2012;2:4. 